\title{
Communication blocks and the power of rethinking
}

\section{Abi Berger}

General Practitioner, London, UK

Correspondence to DrAbi Berger; journal@fsrh.org

Received 19 July 2017 Accepted 24 August 2017
CrossMark

To cite: Berger A. J Fam Plann Reprod Health Care 2017;43:338.
I've been feeling a bit stumped recently. I think of myself as a good detector of psychosomatic illness - by which I mean those instances where real physical illness is driven by life experience or psychosocial distress and not by organic pathology. There are few areas where I encounter more of this than in sexual and reproductive healthcare. I am interested in offering patients suffering from 'mind-body' illness appropriate forms of support, rather than inappropriate treatment and investigation. But recently, I've found the strategies I employ to explain what I think is going on to patients in this situation have not been working as well as they usually do, and wonder why not.

With over 20 years of clinical practice behind me, I'll request investigations where they are clearly indicated and when I think they will provide reassurance for the patient - but otherwise I'm often quietly confident that I can help and support people in making sense of their symptoms without going through all the textbook suggestions to exclude the rare and wonderful diagnoses that 'Dr Google' offers.

One advantage of working in the same practice for a long time is the longitudinal perspective that continuity of care automatically brings, and the light this can shed on new symptoms. Patterns appear and may help to make sense of a new set of symptoms.

Last month I saw a few patients who were not only uncomfortable with the idea that their psyche may be behind their somatic symptoms, but one or two of them were downright hostile to the suggestion. At least one charged me with trying to save money for the health service. I was slightly puzzled and a little offended. Then I realised they were new patients to me. A couple had recently registered with us because their previous GP practice had closed down. Perhaps they weren't used to my style of doctoring? Or perhaps I need to get to know them and earn their trust.
One woman sat down to tell me all about the mystery pain she'd developed since having had a traumatic experience 7 years ago. I acknowledged her concerns and was, I noticed, secretly delighted to find evidence of extensive organic investigation performed within the last few years. I can skip to the chase, I thought. She's had all the tests - it's now a matter of convincing her that she has a functional disorder. I took my time, explained my thinking and reminded her of all the previous investigations that she'd undergone. I even went as far as offering a referral for some counselling. She smiled and nodded. She said she would definitely consider it. We had a good consultation. Or so I thought.

But she returned a few days ago with a request for a "CT scan". She became upset and told me she was fed up with doctors telling her the symptoms were "emotional". We went around in circles. Inside I was wondering how long it would be before I acquiesced to her request. How far would I be pushed before pointing out that the radiation from an unnecessary scan might be dangerous for her?

I am struggling on two counts - to be the best doctor I think I can be, versus the kind of doctor that agrees to do things because the patient wants it even when I think it is wrong. But I also don't want to be the kind of doctor who misses things because I dig my heels in. I realise I have to refine my negotiating skills. And I realise I also have to accept that there are some people for whom Western medicine does not have all the answers. Just as there are some patients who may not be helped by doctors.

Competing interests None declared.

Provenance and peer review Commissioned; internally peer reviewed.

(C) Faculty of Sexual and Reproductive Healthcare of the Royal College of Obstetricians and Gynaecologists (unless otherwise stated in the text of the article) 2017. All rights reserved. No commercial use is permitted unless otherwise expressly granted. 